\title{
Cinza de casca de arroz (CCA) altamente reativa: método de produção e atividade pozolânica
}

High reactive rice husk ash (RHA): production method and
pozzolanic reactivity

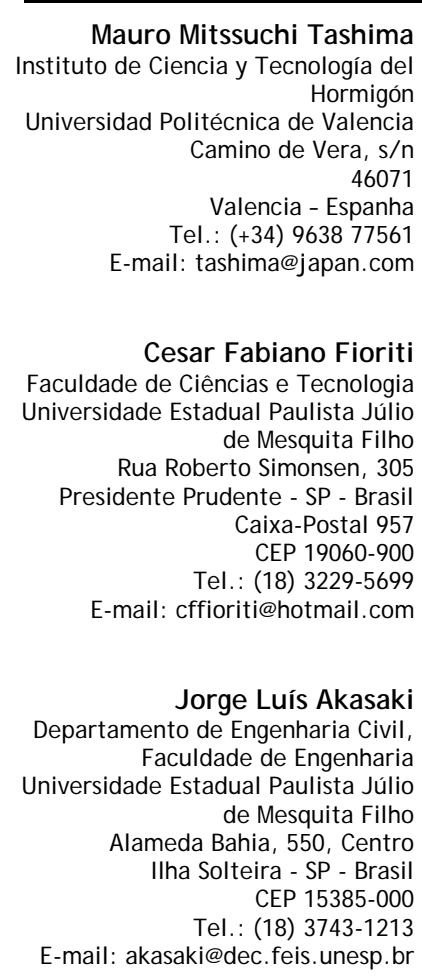

J ordi Payá Bernabeu Instituto de Ciencia y Tecnología del Hormigón Universidad Politécnica de Valencia E-mail: jjpaya@cst.upv.es

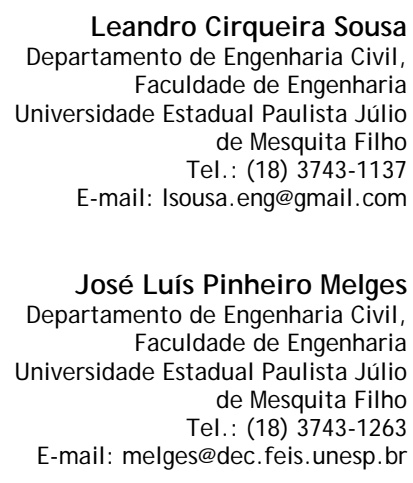

Leandro Cirqueira Sousa Departamento de Engenharia Civil, Faculdade de Engenharia Universidade Estadual Paulista Júlio de Mesquita Filho

Tel.: (18) 3743-1137

E-mail: Isousa.eng@gmail.com

J osé Luís Pinheiro Melges Departamento de Engenharia Civil, Faculdade de Engenharia Universidade Estadual Paulista Júlio de Mesquita Filho Tel.: (18) 3743-1263

E-mail: melges@dec.feis.unesp.br
Mauro Mitssuchi Tashima
Cesar Fabiano Fioriti
J orge Luís Akasaki
J ordi Payá Bernabeu
Leandro Cirqueira Sousa
J osé Luís Pinheiro Melges

\section{Resumo}

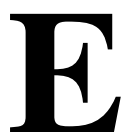

ste trabalho apresenta um método de produção para a obtenção de cinza de casca de arroz (CCA) de elevada reatividade a partir de um processo de combustão não controlado. São detalhados os processos de obtenção da CCA, assim como sua atividade pozolânica. Pela Análise Termogravimétrica (TGA), foi possível quantificar o consumo de portlandita por parte da CCA, ou seja, a reação pozolânica. Adicionalmente, foram preparadas argamassas com diferentes porcentagens de CCA (5\%, 10\% e 15\%) com o objetivo de comprovar sua influência nas propriedades mecânicas. Os resultados obtidos mostram que a CCA em estudo apresenta elevada reatividade, podendo ser utilizada como uma fonte alternativa da sílica ativa (SA).

Palavras-chave: Cinza de casca de arroz. Método de produção. Atividade pozolânica. Análise termogravimétrica.

\section{Abstract}

This paper presents a production method for high reactive rice husk ash (RHA) by means of an uncontrolled combustion process. The production process and pozzolanic activity of RHA are described. The pozzolanic reactivity of RHA was determined by Thermogravimetric Analysis (TGA). Additionally, mortars with different percentages of RHA (5\%,10\% and 15\%) were prepared to verify their influence on mechanical strength. The results show that RHA presents high pozzolanic reactivity and can be used as an alternative source of silica fume (SF).

Keywords: Rice husk ash. Production method. Pozzolanic activity. Thermogravimetric analysis.

Recebido em 19/07/11 Aceito em 11/04/12 


\section{Introdução}

A cinza de casca de arroz (CCA) é um subproduto proveniente da queima da casca de arroz que normalmente vem sendo descartado de forma inadequada no meio ambiente, o que gera sérios problemas ambientais. O processo de queima da casca de arroz para a geração de energia é o grande responsável por essa imensa quantidade de CCA. Somente em 2010, no Brasil, a produção de arroz foi de aproximadamente 12 milhões de toneladas (IBGE, 2011).

A CCA é uma pozolana extremamente atrativa para ser utilizada na confecção de pastas, argamassas e concretos, especialmente quando obtida pela combustão controlada da casca, tendo como característica uma elevada atividade pozolânica.

Atualmente, são ainda as empresas beneficiadoras de arroz as principais consumidoras da casca como combustível para a secagem e parboilização do cereal. Como se trata, geralmente, de empresas de pequeno porte, não possuem processos para aproveitamento e descarte adequados das cinzas produzidas, que são geralmente depositadas em terrenos baldios ou lançadas em cursos d’água, ocasionando poluição e contaminação de mananciais. Todavia, algumas cooperativas no Estado do Rio Grande do Sul estão há algum tempo comercializando CCA para centrais de concreto e outras atividades industriais. Para atividades industriais específicas já está sendo produzida sílica gel e CCA branca. Evidentemente, o custo é bem maior, mas substitui outras fontes industriais de sílica com vantagens financeiras. Para minimizar o problema, órgãos ambientais têm buscado regulamentar o descarte dessas cinzas.

Diante disso, o não aproveitamento desse material não pode mais ser aceito pela sociedade. Por isso, muitos trabalhos vêm sendo desenvolvidos com o intuito de utilizar esse produto em diversos setores industriais, de maneira especial na indústria da construção civil.

Queimada a baixas temperaturas, a casca de arroz gera uma cinza com certo teor de carbono e, por isso, possui uma coloração escura. Por outro lado, quando o processo de combustão realiza-se de forma completa, o material obtido resulta numa cinza de cor acinzentada, branca ou púrpura, dependendo das impurezas presentes e das condições de queima. É consenso na literatura que variáveis como temperatura de queima, tempo de residência, atmosfera de calcinação e taxa de aquecimento influenciem diretamente tanto nas propriedades físico-químicas quanto nas estruturas morfológicas da CCA.
Independentemente do processo de queima da casca para a obtenção da cinza de arroz, a cinza resultante possui um teor de sílica da ordem de $74 \%$ a $97 \%$. A influência do tipo de queima está mais relacionada à morfologia da sílica presente na cinza. A temperatura atingida durante a combustão é fator determinante para o aparecimento da sílica em estado amorfo (mais reativa) ou em estado cristalino (TASHIMA; SILVA; AKASAKI, 2007).

De acordo com Payá et al. (2001), quando a temperatura de combustão é maior que $600{ }^{\circ} \mathrm{C}$, é obtida uma cinza parcialmente cristalina e, consequentemente, sua atividade pozolânica tornase muito menor.

Segundo Sugita et al. (1992), se a casca for préaquecida a uma temperatura de $300-350{ }^{\circ} \mathrm{C}$ por um tempo determinado e depois levada a temperaturas de até $1.000{ }^{\circ} \mathrm{C}$, é possível que a cinza obtida nesse processo não apresente nenhuma fase cristalina.

$\mathrm{O}$ aumento da temperatura de queima diminui a quantidade de carbono presente na sílica, resultando numa diferença de coloração da CCA. Quanto menor a quantidade de carbono, mais clara é a cinza, variando desde uma cor cinza-escuro até o branco-rosado. A quantidade de carbono tem grande influência na absorção de água, já que as moléculas de carbono são extremamente finas, o que gera um aumento na absorção de água. Portanto, normalmente se associa a cinza amorfa a uma coloração escura, e cinza cristalina a uma coloração mais clara (TASHIMA; SILVA; AKASAKI, 2007; VASCONCELOS; AKASAKI, 2010).

Chao-Lung, Anh-Tuan e Chun-Tsun (2011) investigaram os efeitos da adição de CCA do Vietnã do Sul nas propriedades do concreto (resistência à compressão, resistividade elétrica e velocidade de pulso ultrassônico). Os resultados mostraram que a CCA pode ser aplicada como material pozolânico e tem efeito positivo sobre a resistência à compressão. Também indicaram que, em até $20 \%$, o CCA pode ser vantajoso em substituição parcial do cimento sem prejudicar a resistência e propriedades de durabilidade do concreto.

Cordeiro et al. (2011) estudaram o efeito da distribuição de tamanho de partícula e área superficial específica sobre a atividade pozolânica de cinzas residuais da CCA por granulometria a laser BET, áreas de superfície específica pelo método Blaine, distribuição de volume de poros por porosimetria de intrusão de mercúrio, textura da superfície por microscopia eletrônica de varredura, atividade pozolânica utilizando o 
método de argamassa de cimento, e atividade com cal utilizando o método de Chapelle. A partir dos resultados, concluiu-se que não foi identificada correlação entre a atividade pozolânica e a área superficial específica utilizando o método BET, uma observação que é particularmente relacionada com a natureza celular da estrutura interna da RHA.

Para avaliar a consequência dessas variáveis na reação pozolânica da CCA, podem-se empregar distintas técnicas, tais como análises químicas, difração de raios $X$, ensaios mecânicos em argamassas/concretos e algumas técnicas instrumentais como, por exemplo, medidas de condutividade elétrica e a termogravimetria.

A Análise Termogravimétrica (TGA) é uma técnica instrumental que consiste em medir perdas de massa em função da variação da temperatura. Essas perdas de massa são fruto de reações químicas produzidas pela desidratação dos silicatos, aluminatos, silicoaluminatos e hidróxido de cálcio gerados na hidratação do cimento Portland. Portanto, com essa técnica é possível avaliar a formação de silicatos e aluminatos devido à adição de um material pozolânico, isto é, pode-se quantificar o consumo do hidróxido de cálcio devido à pozolana.

Essa técnica foi utilizada para avaliar a pozolanicidade da CCA deste trabalho, que foi obtida através de um método de produção de CCA, simples, sem controle de temperatura, que obtém CCAs de elevado caráter pozolânico, com coloração clara, ou seja, baixo teor de carbono, e que pode dispensar a necessidade de moagem para a confecção de concretos de alto desempenho (CAD).

Muthadhi e Kothandaraman (2010) produziram amostras de CCA sob várias condições de incineração, e a reatividade das cinzas foi estabelecida por várias técnicas, como Difração de Raios X e Microscopia Eletrônica de Varredura Estudo (SEM).

Dessa forma, o presente trabalho avalia a fixação da cal, ou seja, o consumo do hidróxido de cálcio provocado pela adição da sílica ativa (SA) e da
CCA, nas idades de 3, 7, 14 e 28 dias de cura, através da TGA, microscopia eletrônica e resistência mecânica à flexão e à compressão. Para isso foram avaliadas pastas de cimento $\mathrm{e}$ cimento/pozolana com relação água/aglomerante de 0,5 e substituições de 5\%, 10\% e 15\% de pozolana em relação à massa de cimento.

Neste trabalho está-se buscando não somente benefícios econômicos e ecológicos, mas também, principalmente, benefícios tecnológicos ao introduzir a CCA em matrizes de cimento.

\section{Material e métodos}

\section{Cimento Portland}

O cimento Portland utilizado para a produção de argamassas e pastas de cimento foi o CEM I 52,5R, produzido por Lafarge Asland, na Espanha. Trata-se de um cimento com mais de 95\% de clínquer, ou seja, um cimento puro, que apresenta como resistência aos 28 dias o valor de 52,5 MPa. A Tabela 1 apresenta a composição química desse cimento. A escolha desse tipo de cimento foi realizada para evitar ao máximo a interferência de outras adições na análise da atividade pozolânica da CCA.

\section{Sílica Ativa (SA)}

A SA utilizada nesta pesquisa é um produto decorrente do processo de fabricação do silício metálico ou do ferro-silício, de onde é gerado o gás $\mathrm{SiO}$, que, ao sair do forno elétrico, oxida-se formando o $\mathrm{SiO}_{2}$, sendo então captado por filtros de mangas e devidamente armazenado em silo para sua comercialização. Encontra-se em estado densificado e apresenta um diâmetro médio de 23,25 $\mu \mathrm{m}$. A composição química da SA é apresentada na Tabela 2, e o difratograma de raios $X$ é mostrado na Figura 1(a). Pelo difratograma apresentado verifica-se que a SA em estudo apresenta pequenos picos de material cristalino (cristobalita e quartzo), porém se trata de um material predominantemente amorfo, ou seja, de elevada pozolanicidade.

Tabela 1 - Caracterização química do cimento Portland CEM I 52,5R

\begin{tabular}{c|c|c|c|c|c|c|c|c}
\hline & $\mathrm{SiO}_{2}$ & $\mathbf{A l}_{2} \mathbf{O}_{3}$ & $\mathbf{F e}_{2} \mathbf{O}_{3}$ & $\mathbf{C a O}$ & $\mathbf{M g O}$ & $\mathbf{S O}_{3}$ & $\mathbf{K}_{2} \mathbf{O}$ & $\mathbf{N a}_{2} \mathbf{O}$ \\
\hline CEM I 52,5R & 20,80 & 4,60 & 4,80 & 65,60 & 1,20 & 1,70 & 1,00 & 0,07 \\
\hline
\end{tabular}


Tabela 2 - Caracterização química da SA e da CCA

\begin{tabular}{c|c|c|c|c|c|c|c|c|c|c}
\hline & $\mathbf{S i O}_{2}$ & $\mathrm{Al}_{2} \mathbf{O}_{3}$ & $\mathbf{F e}_{\mathbf{2}} \mathbf{O}_{3}$ & $\mathbf{C a O}$ & $\mathbf{M g O}$ & $\mathbf{S O}_{3}$ & $\mathbf{N a O}$ & $\mathbf{K}_{\mathbf{2}} \mathbf{0}$ & $\mathbf{P F}$ & $\begin{array}{c}\text { Massa } \\
\text { específica } \\
\left(\mathbf{g} / \mathbf{c m}^{3}\right)\end{array}$ \\
\hline SA & 91,73 & 0,29 & 0,14 & 0,37 & 0,36 & 0,54 & - & - & 4,61 & 2,20 \\
\hline CCA & 83,53 & 1,42 & 0,86 & 1,79 & 0,36 & 0,45 & 0,96 & 0,79 & 5,28 & 2,14 \\
\hline
\end{tabular}

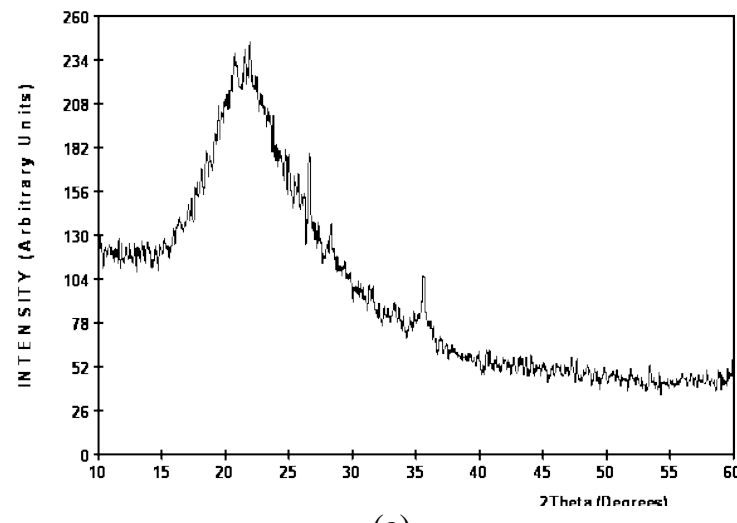

(a)

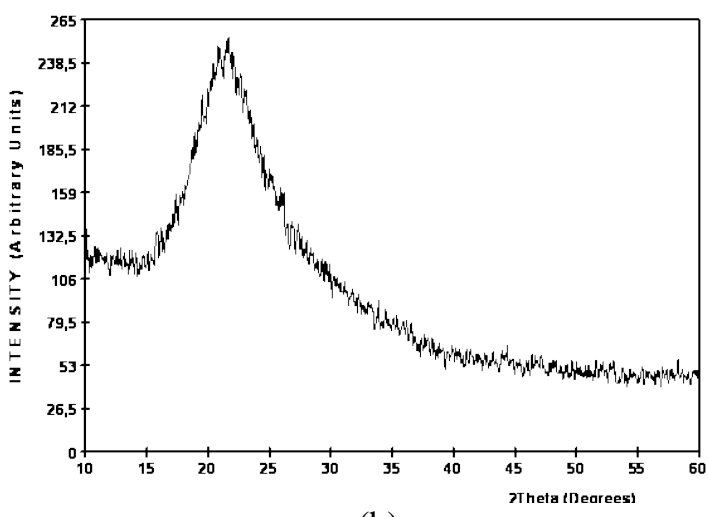

(b)

Figura 1 - (a) Difratograma da SA e (b) difratograma da CCA

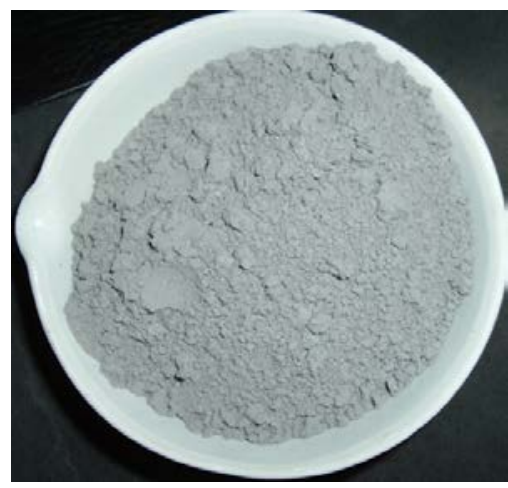

Figura 2 - Amostra de CCA amorfa moída

\section{Cinza de Casca de Arroz (CCA)}

Para a obtenção da CCA foi construído um forno no Laboratório de Engenharia Civil da Unesp, no Campus de Ilha Solteira. O forno utilizado possui capacidade para queimar cerca de $15 \mathrm{~kg}$ de casca de arroz. O processo de combustão inicia-se com o acendimento do fogareiro a gás. Este fica aceso por aproximadamente $10 \mathrm{~min}$. Durante esse período, a casca é colocada no forno em pequenas quantidades, a fim de que se inicie o processo de combustão dela. Passado esse período, o fogareiro é apagado e todo o restante da casca é adicionado ao forno. Coloca-se uma tampa no forno durante todo o processo de queima e, depois de aproximadamente $36 \mathrm{~h}$ de queima, obtém-se a cinza de casca de arroz. Desse processo obtém-se cerca de $1,5 \mathrm{~kg}$ de cinza, ou seja, $10 \%$ do total de casca. Durante o processo de queima da casca de arroz, fez-se o monitoramento da temperatura de queima da casca, no centro do forno, utilizando-se um termopar.

A composição química da cinza e o difratograma de raios X são mostrados na Tabela 2 e na Figura 1(b) respectivamente. A queima da casca de arroz foi realizada sem controle de temperatura, quando foram detectados picos de até $850{ }^{\circ} \mathrm{C}$ durante o processo. A CCA apresenta uma coloração cinzaclaro após a moagem (Figura 2) e, de acordo com a Figura 1(b), observa-se que a CCA em estudo é um material amorfo. Isso é indicado pelo desvio da linha-base entre os ângulos de 15 e 30 graus.

Neste estudo a CCA foi submetida a um processo de moagem durante $20 \mathrm{~min}$, apresentando um diâmetro médio de $11,08 \mu \mathrm{m}$. Para o processo de moagem utilizou-se um moinho de bolas Gabrielli Mill-2 que continha 50 bolas de alumina com 18 
mm de diâmetro, com um peso total de 570 g. O tempo de 20 min de moagem foi definido com base nos resultados apresentados por Tashima (2006) no que tange à influência do tempo de moagem na granulometria da CCA.

\section{Metodologia}

Foram preparadas pastas de cimento e cimento/pozolana em distintas porcentagens (5\%, $10 \%$ e $15 \%$ ) em substituição à massa do cimento e com relação água/aglomerante de 0,5. As pastas foram armazenadas em câmara úmida até a data de ensaio (3, 7, 14 e 28 dias). Antes de serem ensaiadas, as pastas foram submetidas a um processo de moagem em presença de acetona, para interromper o processo de hidratação do cimento. Essa moagem foi realizada utilizando-se um almofariz de ágata; em seguida, as amostras foram secas em estufa a $60{ }^{\circ} \mathrm{C}$ durante $30 \mathrm{~min}$. O material passante na $\# 80 \mu \mathrm{m}$ foi utilizado para o ensaio de análise termogravimétrica.

Para a realização do ensaio de termogravimetria utilizou-se o equipamento TGA 850 Mettler Toledo, que permite medir simultaneamente a curva termogravimétrica (TG) e a curva térmicodiferencial (DTA) sem a necessidade de um material de referência (Single Differential Thermal Analysis, SDTA). O equipamento possui uma balança horizontal com precisão de 0,1 $\mu \mathrm{g}$, um forno e sensores de temperatura que estão conectados a um computador.

A Análise Termogravimétrica (TGA) foi uma das técnicas empregadas neste trabalho para a determinação da atividade pozolânica das pozolanas. O método consiste em medir perdas de massa devido a variações de temperatura. Ao estudarem-se pastas de cimento com e sem a substituição de pozolanas, o que se mede são as perdas de massa devido à desidratação da pasta de cimento. Essa perda é devida principalmente aos seguintes processos de desidratação:

(a) $\mathrm{Ca}(\mathrm{OH}) 2 \rightarrow \mathrm{CaO}+\mathrm{H} 2 \mathrm{O}$;

(b) $\mathrm{SCH} \rightarrow \mathrm{SC}+\mathrm{xH} 2 \mathrm{O}$;

(c) $\mathrm{ACH} \rightarrow \mathrm{AC}+\mathrm{yH} 2 \mathrm{O}$; e

(d) $\mathrm{SACH} \rightarrow \mathrm{SAC}+\mathrm{zH} 2 \mathrm{O}$.

Na curva TG avalia-se a variação de massa da amostra em função da temperatura e tempo, de modo que podem ser produzidas tanto perdas como ganhos de massa. Essas variações de massa são características das reações químicas que se produzem durante o experimento. A curva derivada termogravimétrica (DTG) mostra informações sobre a velocidade de perda ou ganho de massa em função da temperatura e do tempo.
Esse gráfico permite identificar com maior facilidade as alterações de massa, especialmente quando as perdas são muito pequenas ou também quando existem processos químicos com temperaturas muito próximas.

Para a realização desse tipo de análise, utilizaramse crisóis de alumínio de $100 \mu \mathrm{l}$ com tampa selável. Essa tampa possui um orifício que ajuda na obtenção de uma atmosfera autogerada. Isso faz com que a amostra esteja por mais tempo em equilíbrio com sua fase gasosa, dando como resultado uma melhor separação entre os processos de perdas de massa consecutivos e, consequentemente, um deslocamento de picos a temperaturas superiores.

O forno está dotado de uma resistência elétrica que mantém uniforme a temperatura ao redor da amostra e pode atingir temperaturas de até 1.100 ${ }^{\circ} \mathrm{C}$. Essa temperatura é medida por um termopar, que está conectado com um computador. O computador recebe esses dados através do programa Mettler Toledo STARe Thermal Analysis System. É nesse programa que se estabelecem o intervalo de temperatura do ensaio e a velocidade de aquecimento.

As análises com pastas de cimento e cimento/pozolana realizaram-se com uma atmosfera inerte de nitrogênio, com um fluxo de $75 \mathrm{ml} / \mathrm{min}$ e uma velocidade de aquecimento de 10 ${ }^{\circ} \mathrm{C} / \mathrm{min}$, sendo o intervalo de temperatura do ensaio entre $35^{\circ} \mathrm{C}$ e $600{ }^{\circ} \mathrm{C}$.

A microscopia eletrônica de varredura foi utilizada para verificar a morfologia e a composição das pozolanas em estudo. Também foi utilizada para a visualização de produtos de hidratação em pastas de cimento e cimento/pozolanas. As imagens de microscopia foram obtidas a partir de elétrons secundários gerados pelo equipamento modelo JEOL JSM6300, e em todos os casos foi utilizada uma voltagem de $20 \mathrm{KV}$ para a obtenção das imagens.

Para melhorar a condutividade elétrica dos materiais, as amostras eram previamente recobertas por um banho de ouro. Com isso, obtinham-se imagens mais nítidas. Esse recobrimento foi realizado utilizando-se o equipamento BALTEC SCD 005. O tempo de exposição da amostra ao ouro foi de $90 \mathrm{~s}$, com uma intensidade de $40 \mathrm{~mA}$, a uma distância de $5 \mathrm{~mm}$. Todo esse procedimento de recobrimento foi realizado com uma pressão de 2,4×10-2 mbar.

Na determinação de resistências mecânicas (flexão e compressão) de argamassas utilizou-se como referência a norma espanhola UNE-EN 196-1 (ASOCIACIÓN..., 1996). Todos os procedimentos 
de mistura, moldagem, adensamento e cura estão especificados na referida norma.

Vale ressaltar que os corpos de prova possuíam dimensões de $4 \mathrm{~cm}$ x $4 \mathrm{~cm}$ x $16 \mathrm{~cm}$ e que seu adensamento foi realizado mecanicamente, ou seja, utilizando-se uma mesa compactadora. No processo de cura, os corpos de prova eram mantidos em uma câmara úmida a $20^{\circ} \mathrm{C}$ e imersos em água até a idade de ruptura.

\section{Resultados e discussões}

\section{Análise Termogravimétrica (TGA)}

Esse ensaio foi realizado com o intuito de verificar-se a fixação da cal $(\mathrm{CH})$ quando da adição de uma pozolana. A Tabela 3 mostra os valores de fixação da cal utilizando tanto a CCA como a SA em diferentes porcentagens de substituição, em relação à massa de cimento. A Figura 3 mostra o resultado do ensaio de TGA para uma pasta de cimento com 5\% de CCA aos 3 dias de cura. A curva TG mostra a perda de massa (água) em função da temperatura. Já a curva DTG fornece informações a respeito da velocidade com que ocorre a perda de massa, em função da temperatura e do tempo.
Os valores de fixação de cal são calculados a partir da curva DTG. O primeiro pico, temperatura de aproximadamente $120-150{ }^{\circ} \mathrm{C}$, mostrado na Figura 3 , indica a perda de massa devido à desidratação dos produtos formados durante a hidratação do cimento Portland (C-S-H, C-A-H, C-A-S-H); já o segundo pico (aproximadamente $550{ }^{\circ} \mathrm{C}$ ) indica a perda de massa devido à desidroxilação do hidróxido de cálcio (portlandita).

Na Tabela 3 pode-se verificar a influência do teor de substituição na fixação da portlandita. Para ambas as pozolanas, quanto maior o teor de substituição, maior a fixação de $\mathrm{CH}$ aos 14 e 28 dias de cura. Para idades curtas (3 e 7 dias de cura), o que se verifica é que os valores de fixação da cal não possuem a mesma tendência do que para longas idades. Esse fato é devido à atuação em paralelo dos chamados efeito pozolânico e efeito partícula, fazendo com que haja valores aleatórios de fixação de cal. Aos 28 dias de cura, observa-se que as pastas com adição da CCA apresentam um maior consumo de $\mathrm{CH}$ em relação às pastas com AS; conforme se aumenta a porcentagem de pozolana, mais se aumenta a fixação de cal.

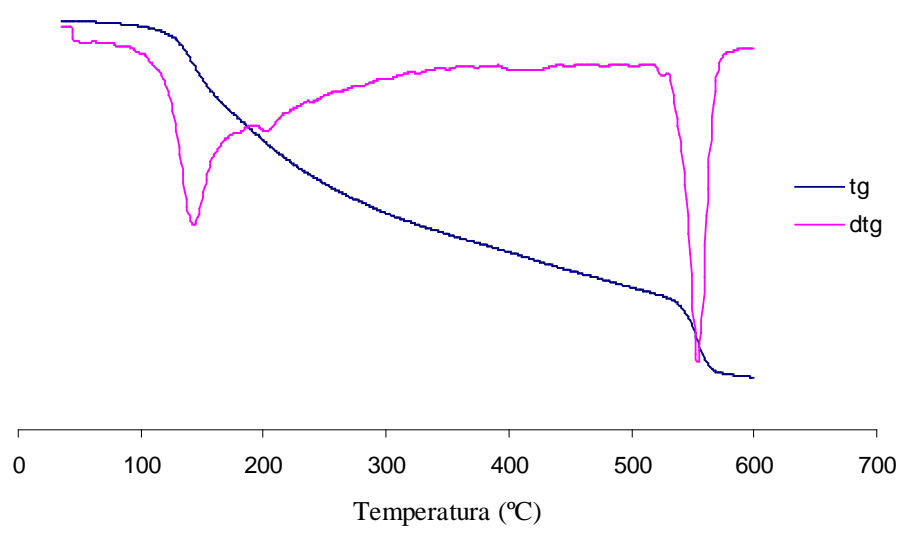

Figura 3 - Curvas TG e DTG para pastas de cimento/5\%CCA com 3 dias de cura

Tabela 3 - Fixação da cal em função da porcentagem de substituição e da idade de cura

\begin{tabular}{c|c|r|r|r|r}
\hline \multirow{2}{*}{ Pozolana } & \multirow{2}{*}{ Substituição (\%) } & \multicolumn{4}{|c}{ Tempo de cura (dias) } \\
\cline { 3 - 6 } & & $\mathbf{3}$ & $\mathbf{7}$ & $\mathbf{1 4}$ & $\mathbf{2 8}$ \\
\cline { 3 - 6 } & & \multicolumn{4}{|c}{$\%$ de Cal fixada } \\
\hline CCA & \multirow{2}{*}{$5 \%$} & $-1,32$ & 0,56 & 13,65 & 11,64 \\
\cline { 3 - 6 } SA & \multirow{2}{*}{ CCA } & 17,28 & $-1,15$ & 11,07 & 5,24 \\
\hline \multirow{2}{*}{ SA } & \multirow{2}{*}{$10 \%$} & 7,29 & $-6,29$ & 12,65 & 22,95 \\
\cline { 3 - 6 } & & 16,46 & 0,07 & 19,86 & 12,98 \\
\hline CCA & \multirow{2}{*}{ SA } & 8,67 & 10,35 & 16,07 & 31,28 \\
\hline \multirow{2}{*}{$15 \%$} & 16,98 & 8,67 & 20,81 & 18,03 \\
\hline
\end{tabular}

156 Tashima, M. M.; Fioriti, C. F.; Akasaki, J. L.; Bernabeu, J. P.; Sousa, L. C.; Melges, J. L. P. 
A Figura 4 mostra as curvas DTG obtidas para uma pasta de cimento com 5\% de CCA para diferentes idades. Verifica-se que as perdas de massa para as diferentes idades são obtidas sempre a uma mesma temperatura, variando apenas a quantidade de água perdida. O mesmo pode ser observado para todas as demais pastas. Como exemplos são colocadas as curvas DTG para pastas com $10 \%$ de SA para diferentes idades (Figura 5).

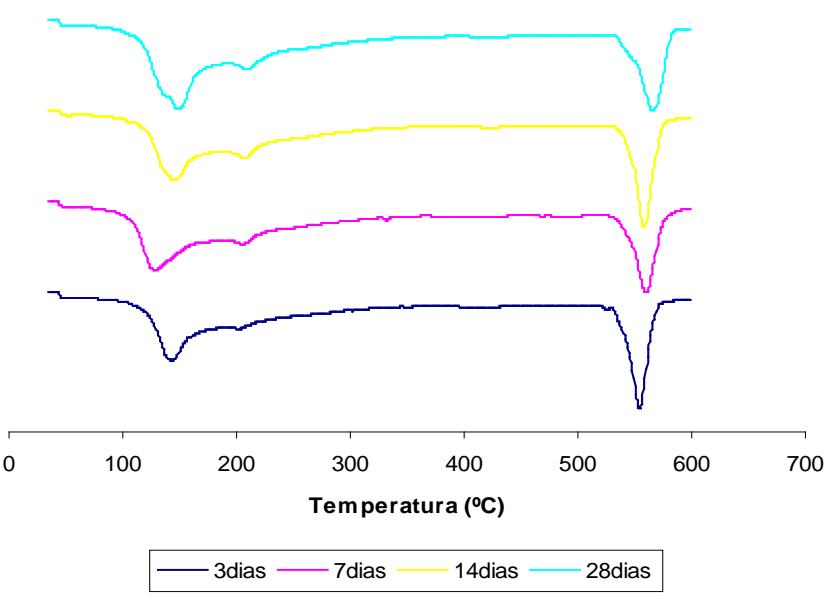

Figura 4 - Curvas DTG para pastas de cimento com 5\% de CCA para diferentes idades

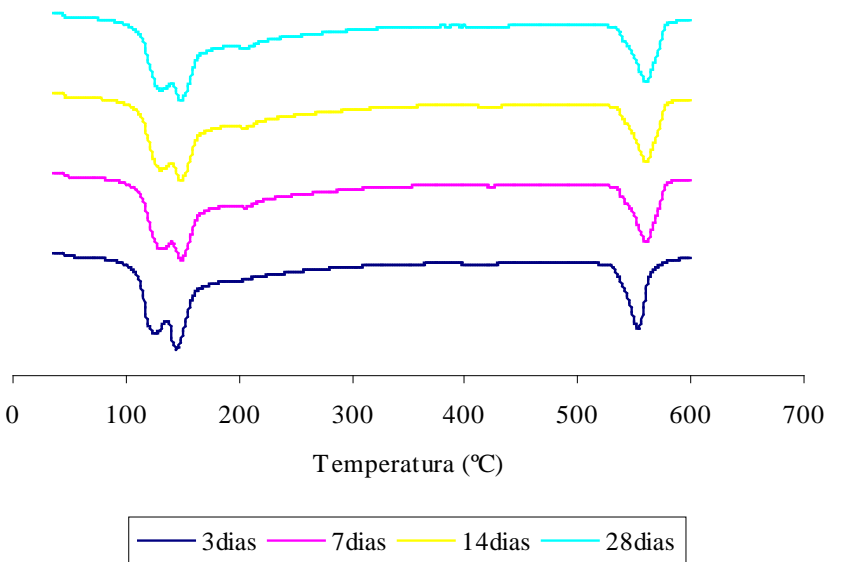

Figura 5 - Curvas DTG para pastas de cimento com $10 \%$ de SA para diferentes idades
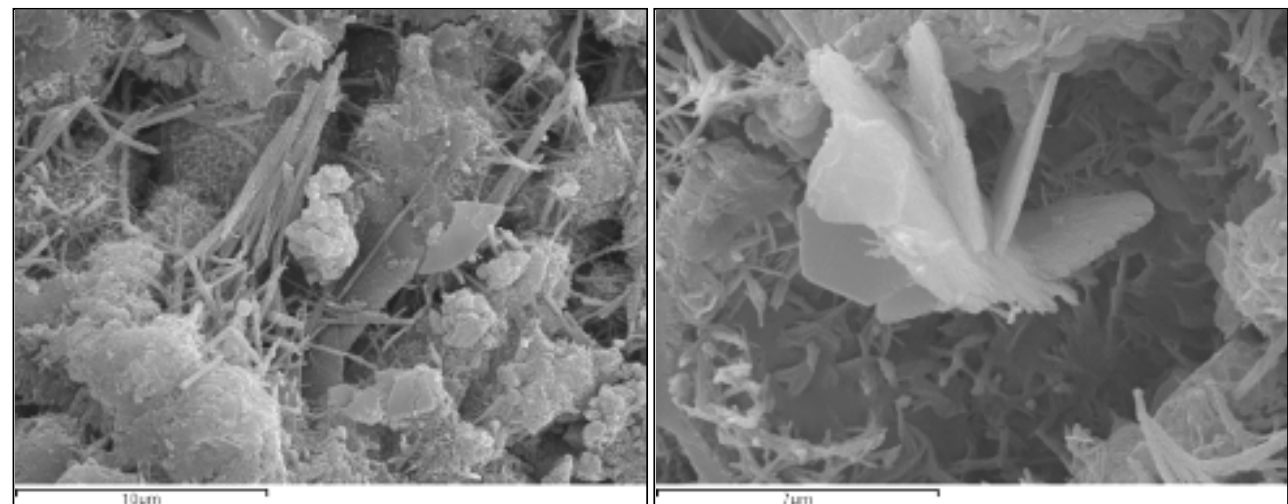

Figura 6 - Produtos de hidratação de pastas de cimento com 5\% de CCA aos 3 dias de cura (C-S-H e etringita) 


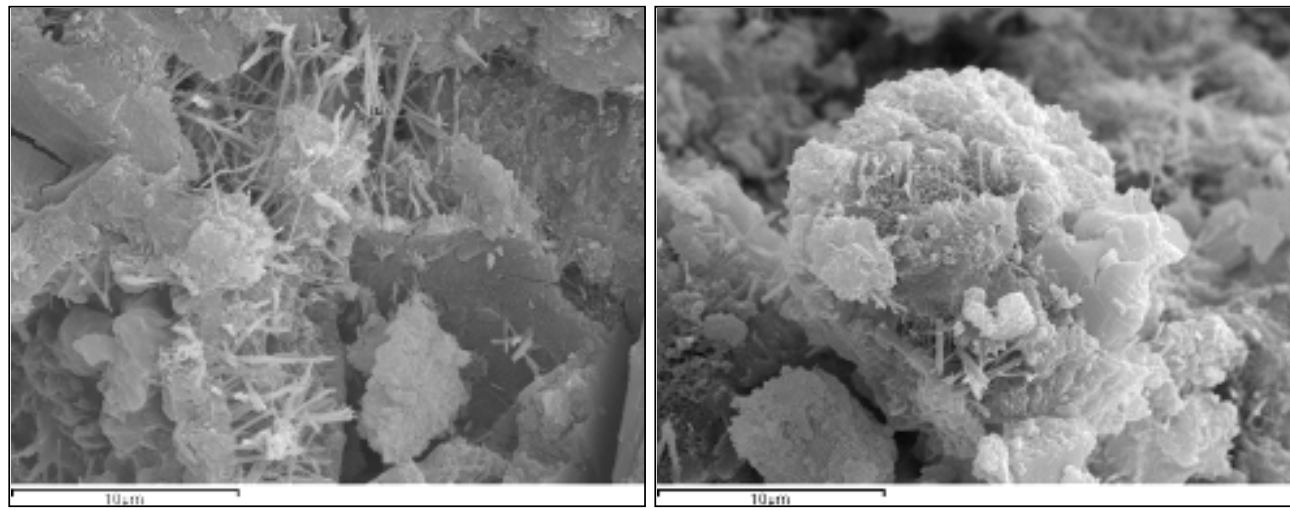

Figura 7 - Produtos de hidratação de pastas de cimento com 10\% de CCA aos 3 dias de cura
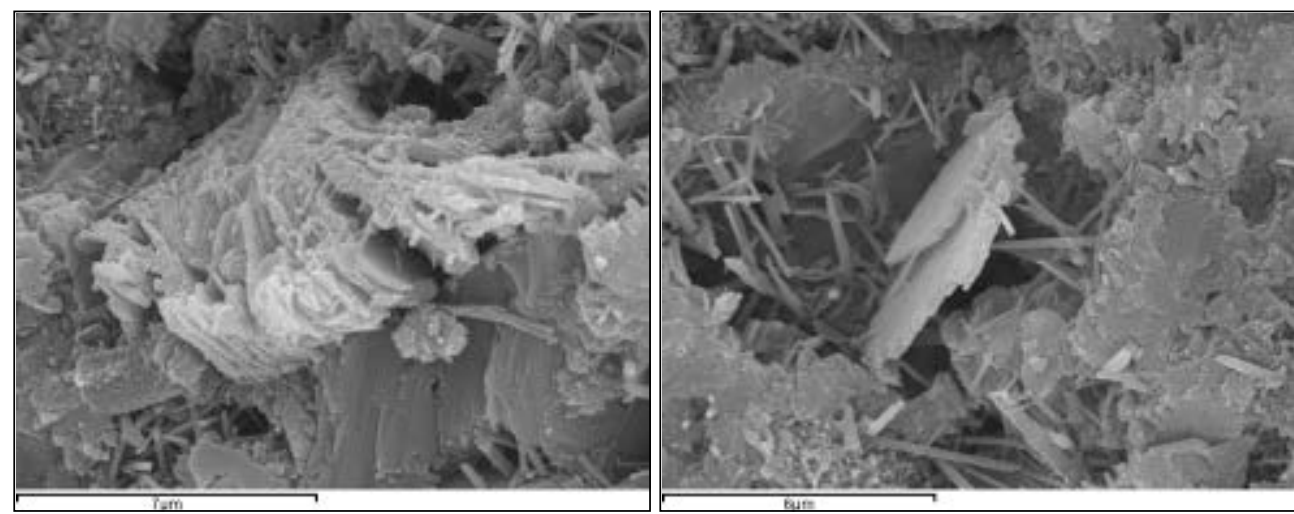

Figura 8 - Produtos de hidratação de pastas de cimento com 15\% de CCA aos 3 dias de cura (C-S-H e etringita)
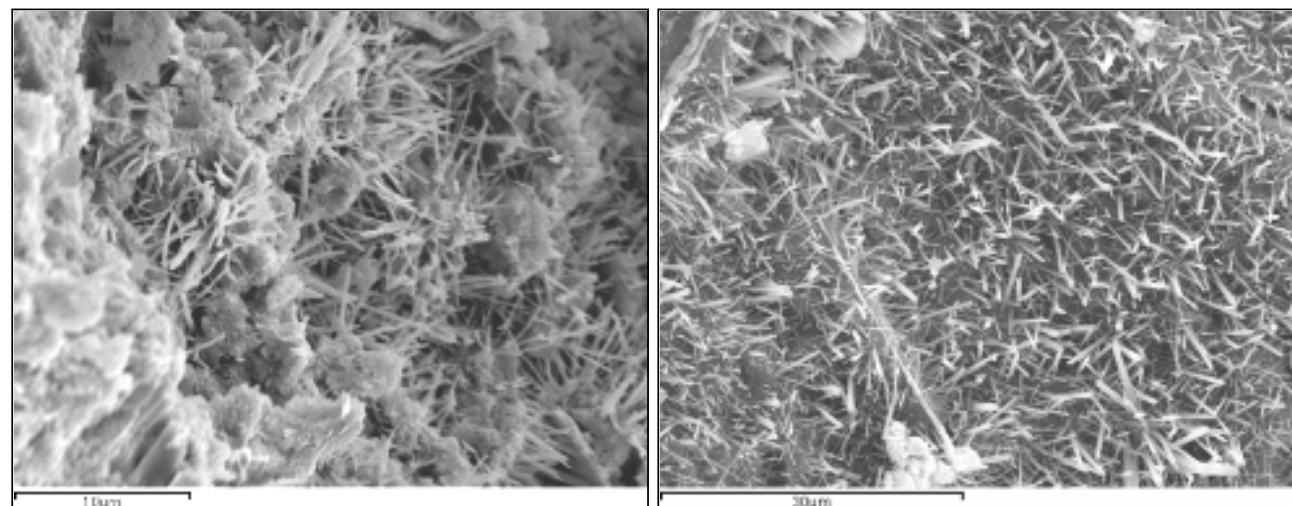

Figura 9 - Etringita em pastas de cimento com $10 \%$ de SA aos 3 dias de cura

\section{Microscopia eletrônica das pastas}

A seguir são mostradas algumas micrografias tomadas de pastas de cimento e cimento/pozolana para a visualização da formação de produtos de hidratação. Nas Figuras 6, 7 e 8 verifica-se a presença de C-S-H tanto em estado amorfo como em estado cristalino. Observa-se também a presença de etringita.
Na sequência são apresentadas micrografias de pastas de cimento com $10 \%$ de SA aos 3 dias de cura. Pode-se observar a existência de grande quantidade de etringita nessas pastas (Figura 9).

Aos 28 dias de cura, observa-se que a presença de cristais de SCH são mais abundantes. Ainda assim, a etringita pode ser encontrada com bastante facilidade, porém em menor quantidade. A Figura 10 mostra a formação de cristais de hidróxido de cálcio em pastas com 10\% de CCA. 


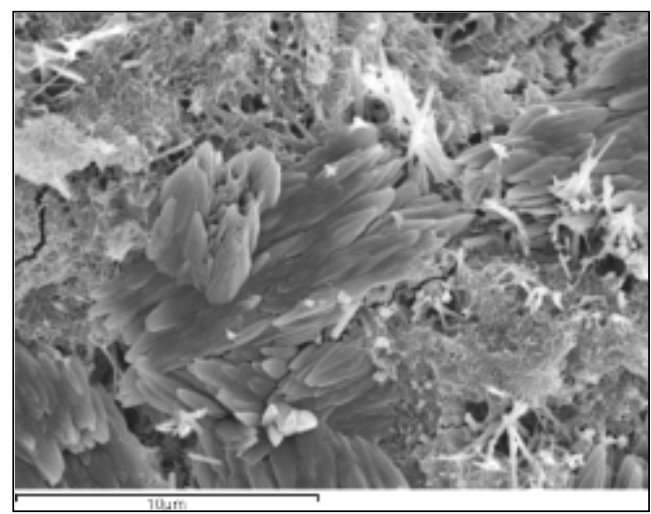

Figura 10 - Cristais de portlandita presentes em pastas de cimento com 10\% de CCA aos 28 dias de cura
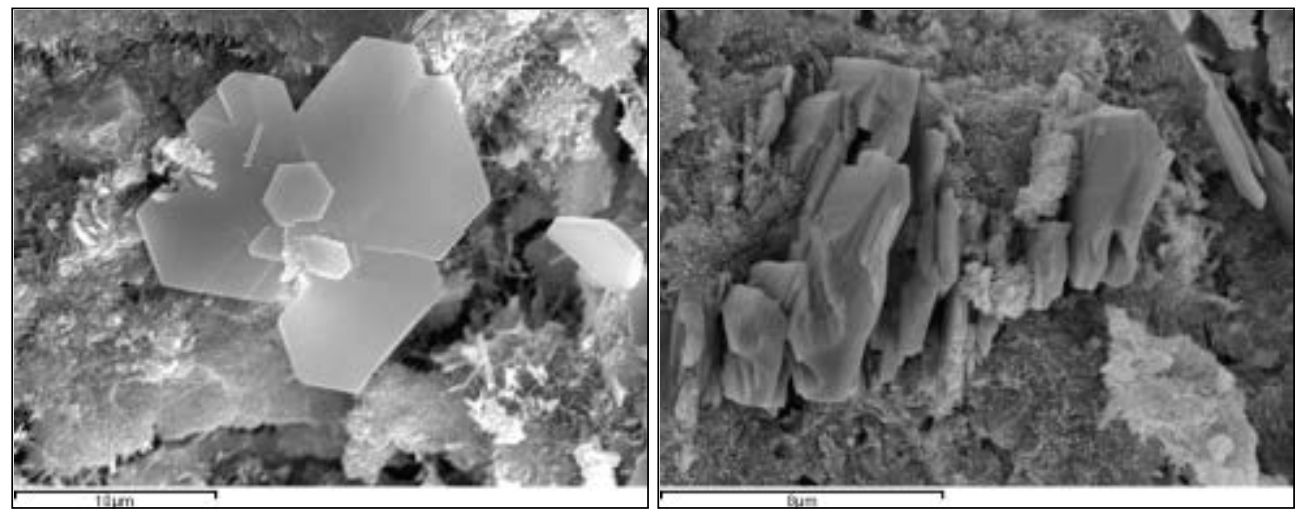

Figura 11 - Produtos de hidratação de pastas de cimento com $10 \%$ de SA aos 28 dias de cura: portlandita
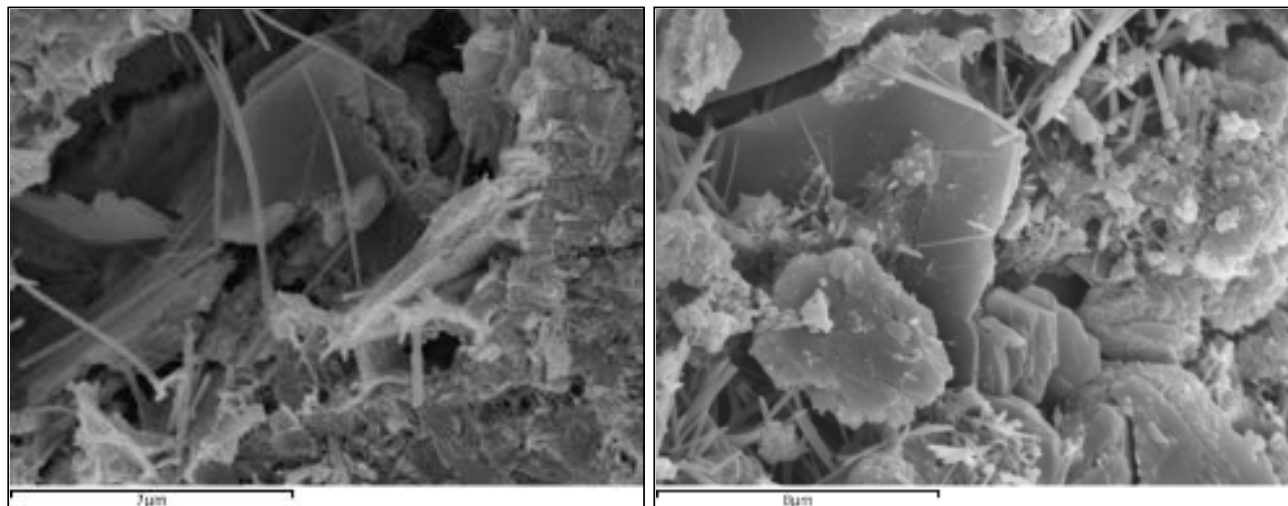

Figura 12 - Silicatos de cálcio hidratados em pastas de cimento com $15 \%$ de CA e $15 \%$ de SA respectivamente

Nas pastas de cimento com $10 \%$ de SA encontraram-se cristais de portlandita em grande quantidade (Figura 11). Já para pastas com CCA, os cristais de $\mathrm{CH}$ foram encontrados em menor quantidade.

A Figura 12 mostra a formação de silicatos de cálcio hidratados (C-S-H) em pastas de cimento com $15 \%$ de CCA e $15 \%$ de SA respectivamente.
Ao redor desses cristais há a presença de pequenos filamentos finos, conhecidos como etringita.

\section{Resistências mecânicas}

Na Figura 13 são mostrados os resultados médios de resistência à flexão das argamassas em estudo. Os resultados mostram que, para todas as porcentagens estudadas, as argamassas com adição de CCA apresentam desempenhos superiores em 
relação às argamassas com SA. Também se observa que, para as idades de 3, 7 e 14 dias, os valores de resistência à flexão do traço controle são, geralmente, superiores aos valores apresentados para as argamassas com SA e inferiores aos valores de argamassas com CCA. Já para a idade de 28 dias, verifica-se que as argamassas contendo pozolanas apresentam resistências superiores ao traço controle.

A Figura 14 mostra as resistências à compressão obtidas para argamassas com diferentes porcentagens de SA. Já a Figura 15 mostra os valores para as argamassas com CCA.

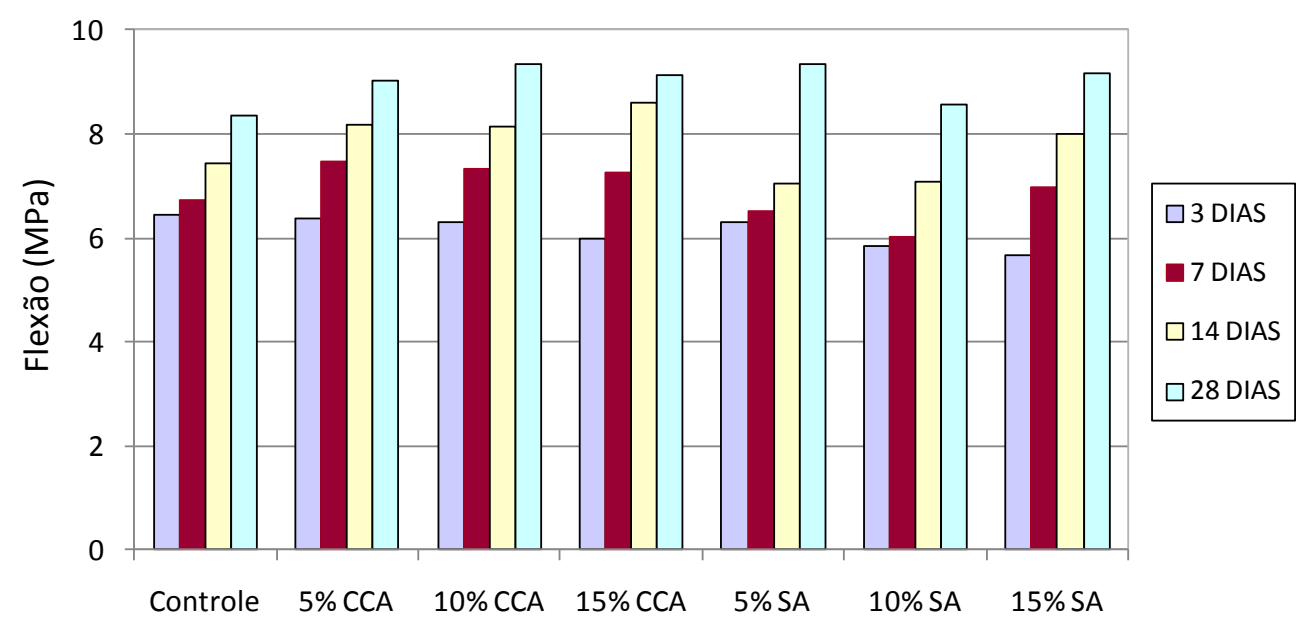

Figura 13 - Gráfico de resistência à flexão

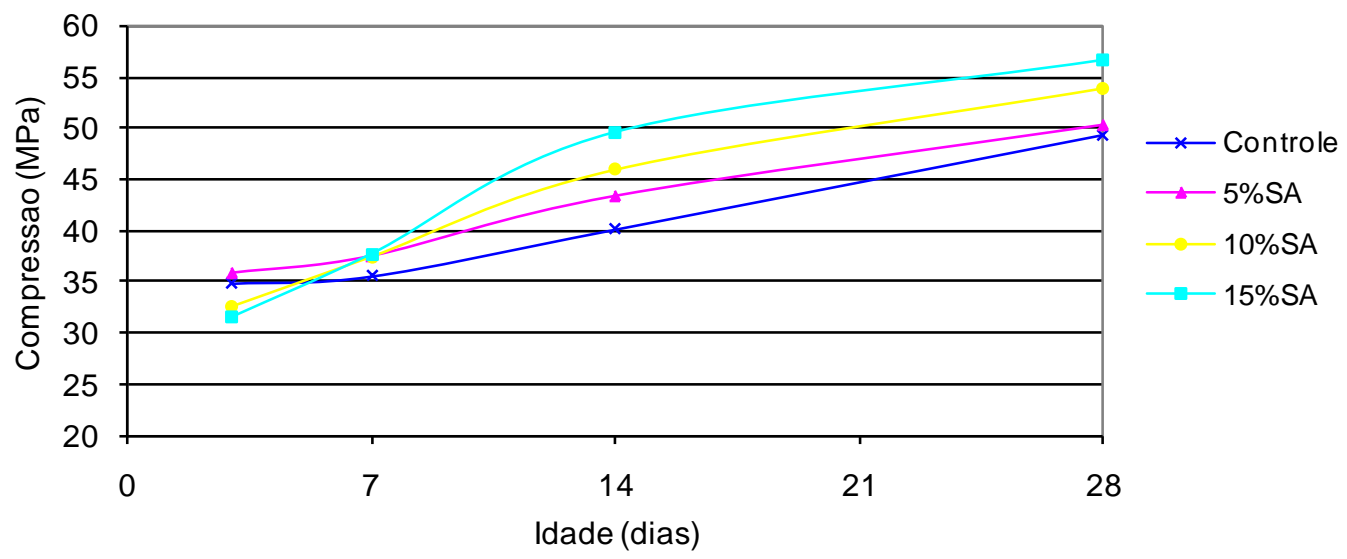

Figura 14 - Resistência à compressão para argamassas com diferentes porcentagens de SA

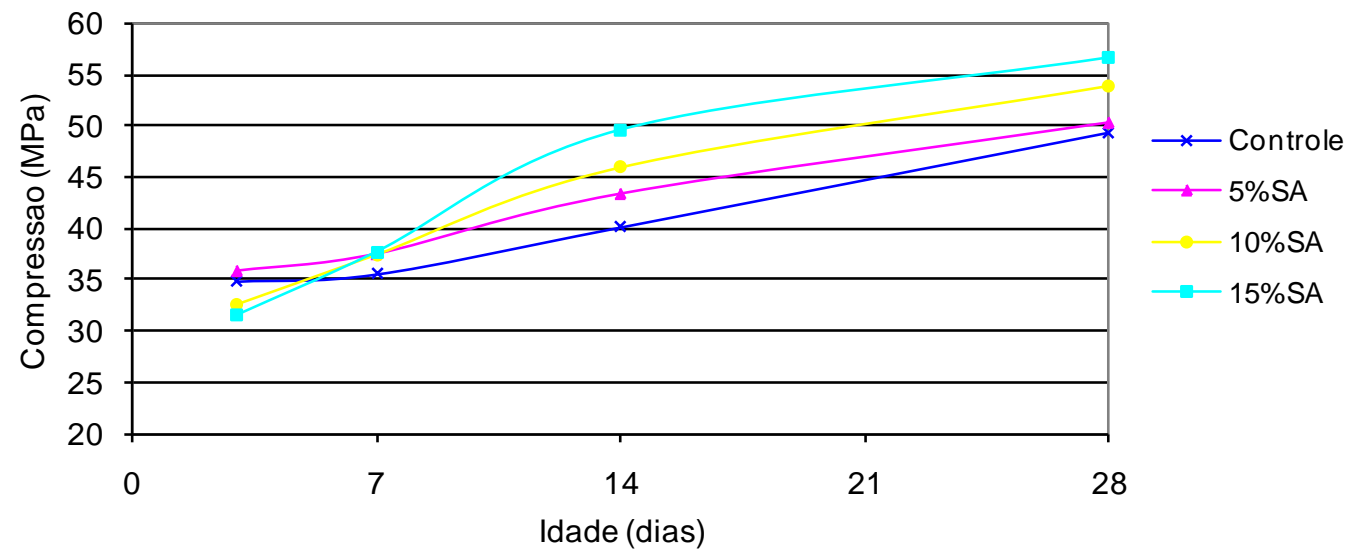

Figura 15 - Resistência à compressão para argamassas com diferentes porcentagens de CCA 
Pelos resultados obtidos, verificou-se que a substituição de cimento por SA ou por CCA, para todas as porcentagens estudadas, melhora a resistência à compressão da argamassa. À medida que se aumentava a porcentagem de substituição, o ganho de resistência aumentava, mesmo retirandose uma parte do cimento (substituição em massa). Esse fato pode ser explicado por introduzir-se um material pozolânico que, além de seu efeito químico, também atua como um fíler, diminuindo o tamanho dos poros e aumentando, assim, a resistência das argamassas.

A Figura 16 mostra um gráfico comparativo entre as resistências obtidas para argamassas com SA e com CCA. Nota-se que, para um mesmo teor de substituição, as argamassas com CCA e com SA apresentam valores de resistência à compressão similares, e superiores ao traço controle.
A seguir são mostrados os ganhos de resistência das argamassas em função do teor de substituição das pozolanas. No caso da CCA (Figura 17), verifica-se que, para todas as porcentagens $\mathrm{e}$ idades estudadas, a introdução da CCA proporciona ganhos de resistência.

Para argamassas com SA (Figura 18), nota-se a mesma tendência que para a CCA. Para a idade de 3 dias, verifica-se que o ganho de resistência é muito pequeno, pois a pozolana ainda não começou a atuar. Entre as idades de 7 e 28 dias, percebe-se claramente o efeito pozolânico tanto da SA como da CCA. Os ganhos de resistência atingidos para argamassas com $15 \%$ de substituição, aos 14 dias de idade, chegam a mais de $40 \%$ tanto para as argamassas com SA como para as argamassas com CCA.

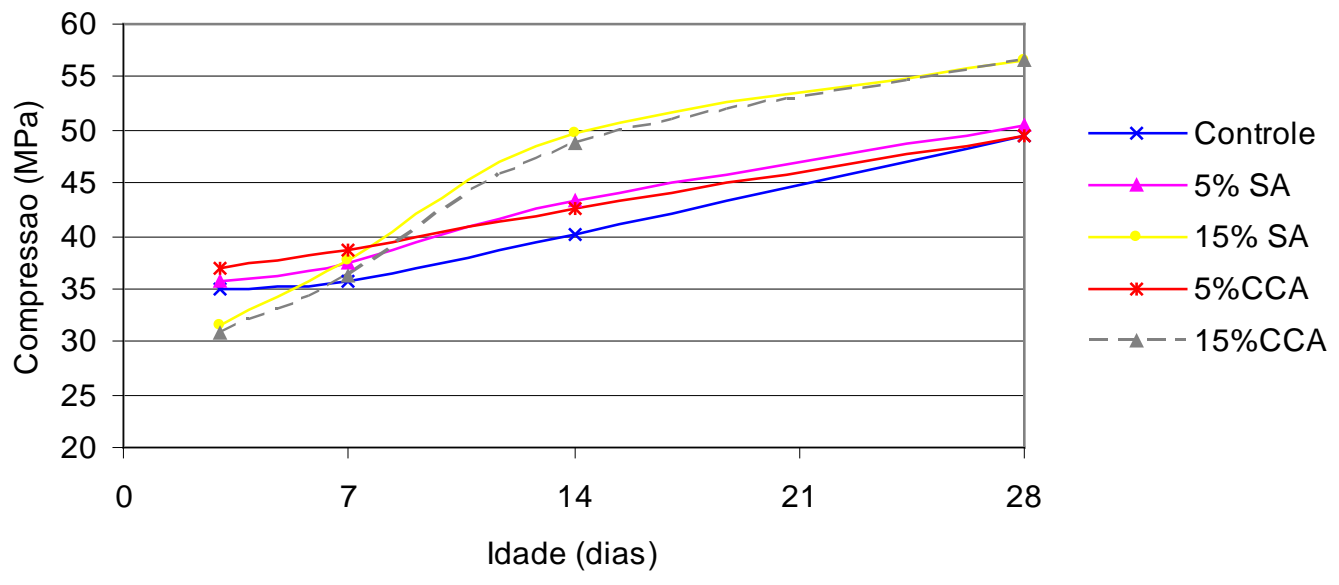

Figura 16 - Gráfico comparativo de resistência à compressão para argamassas com diferentes porcentagens de SA e CCA

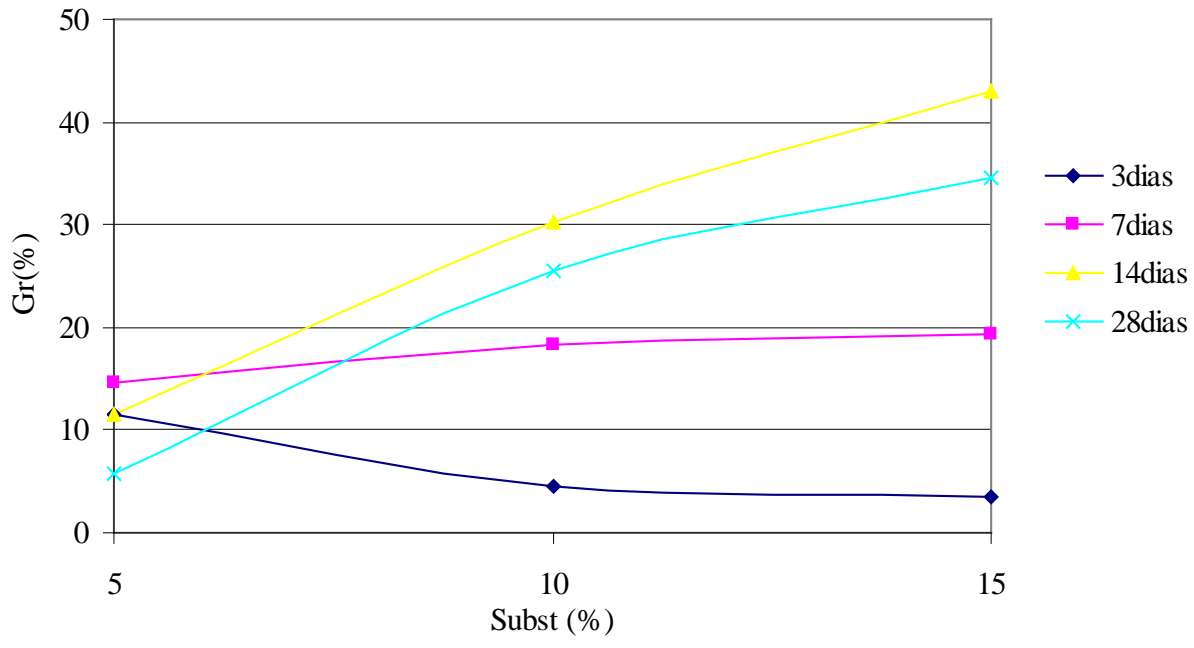

Figura 17 - Ganho de resistência à compressão em função do teor de substituição para argamassas com CCA 


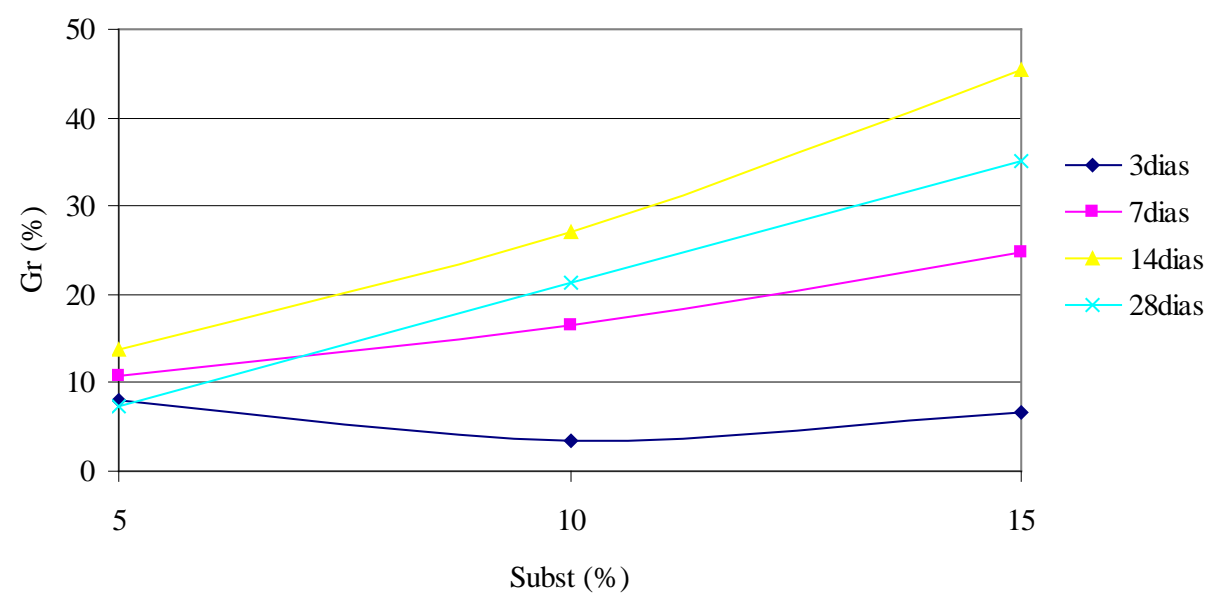

Figura 18 - Ganho de resistência à compressão em função do teor de substituição para argamassas com SA

Outro fato notado é que, para ambas as pozolanas em estudo, o ganho de resistência está sempre associado a uma elevada fixação de cal. Isso vem comprovar que o ganho de resistência das argamassas está muito influenciado pela atividade pozolânica, ou seja, pelo consumo da portlandita liberada durante o processo de hidratação do cimento.

\section{Conclusões}

Os resultados obtidos neste trabalho mostram que a CCA produzida sob as condições de queima propostas, ou seja, sem controle de temperatura e com tempo de queima de aproximadamente $36 \mathrm{~h}$, apresenta características adequadas para a utilização como material pozolânico em matrizes de cimento.

No que refere à caracterização química, a CCA apresentou teor de $\mathrm{SiO}_{2}$ de 83,53\%, e quase todo o $\mathrm{SiO}_{2}(99,30 \%)$ apresenta-se em estado amorfo ou reativo. Esse caráter foi confirmado através de ensaios como a difração de raios $\mathrm{X}$, determinação de sílica amorfa e microscopia eletrônica.

A confirmação desse caráter pozolânico foi realizada introduzindo-se o material em matrizes de cimento. Nesse caso, observou-se que a CCA em estudo gera um aumento na fixação da cal, quando comparado com um traço controle; além disso, quando adicionados em argamassas verificase ganhos de resistência de até $40 \%$ em relação ao traço controle.

A reatividade da CCA em estudo é comparável à sílica ativa, o material pozolânico mais reativo que se encontra no mercado atual. Diante desse fato, acredita-se que a CCA pode ser utilizada como uma fonte alternativa da sílica ativa para a produção de argamassas e concretos.

\section{Referências}

CHAO-LUNG, H.; ANH-TUAN, B. L.; CHUNTSUN, C. Effect of Rice Husk Ash on the Strength and Durability Characteristics of Concrete.

Construction and Building Materials, v. 25, n. 9, p. 3768-3772, 2011.

CORDEIRO, G. C. et al. Influence of Particle Size and Specific Surface Area on the Pozzolanic Activity of Residual Rice Husk Ash. Cement and Concrete Composites, v. 33, n. 5, p. 529-534, 2011.

INSTITUTO BRASILEIRO DE GEOGRAFIA E ESTATÍSTICA. Indicadores Conjunturais: produção agrícola. Disponível em: <http://www.ibge.gov.br>. Acesso em: 10 jul. 2011.

MUTHADHI, A.; KOTHANDARAMAN, S. Optimun Production Conditions For Reactive Rice Husk Ash. Materials and Structures, v. 43, n. 9, p. 1303-1315, 2010.

PAYÁ, J. et al. Determination of Amorphous Silica in Rice Husk Ash by a Rapid Analytical Method. Cement and Concrete Research, v. 31, n. 2, p. 227-231, 2001.

SUGITA, S. et al. Evaluation of Pozzolanic Activity of Rice Husk Ash. In: INTERNATIONAL CONFERENCE, $4^{\mathrm{TH}}$, Istambul, 1992. Proceedings... Istambul, 1992, p. 495-512.

TASHIMA, M. M. Cinza de Casca de Arroz Altamente Reativa: método de produção, caracterização físico-química e comportamento em matrizes de cimento Portland. 79 f. Ilha Solteira, 2006. Dissertação (Mestrado em Engenharia Civil) - Escola de Engenharia, Universidade Estadual Paulista, Ilha Solteira, 2006. 
TASHIMA, M. M.; SILVA, E. J.; AKASAKI, J. L. Estudo de Reações Expansivas em Argamassa de Cimento Portland Com Cinza de Casca de Arroz (CCA). HOLOS Environment, v. 7, p. $72-$ 86, 2007.

ASOCIACIÓN ESPAÑOLA DE NORMALIZACIÓN Y CERTIFICACIÓN -

AENOR. UNE-EN 196-1: métodos de ensayo de cementos, parte 1: determinación de las

resistencias mecánicas. Madrid, Espanha. 1996.
VASCONCELOS, A. R. B.; AKASAKI, J. L. Análise da Durabilidade do Concreto de Alto Desempenho Com Adição de Cinza de Casca de Arroz e Borracha de Pneu. Ambiente Construído, Porto Alegre, v. 10, n. 4, p. 77-90, out./dez. 2010.

Revista Ambiente Construído

Associação Nacional de Tecnologia do Ambiente Construído

Av. Osvaldo Aranha, 99 - 3o andar, Centro

Porto Alegre - RS - Brasil

CEP 90035-190

Telefone: +55 (51) 3308-4084

Fax: +55 (51) 3308-4054

www. seer. ufrgs. br/ ambienteconstruido

E-mail: ambienteconstruido@ufrgs.br 